\title{
The Climate Change Awareness and Literacy in Pakistan: Role of Media and Social Actors
}

\author{
Azam Jan*1, Tariq Anwar Khan ${ }^{2-3} \&$ Muhammad Imran Mahsud ${ }^{2-4}$
}

1. Department of Communication \& Media Studies, Hazara University, Mansehra, Pakistan.

2. Department of Political Science \& International Relations, Hazara University, Mansehra, Pakistan.

3. Department of Political Science, Faculty of Social Sciences, University of Punjab, Lahore, Pakistan.

4. School of Politics \& International Relations, Quaid-e-Azam University, Islamabad, Pakistan.

\begin{abstract}
The multidimensional impacts of climate change are increasing the vulnerability of Pakistan day by day. The government of Pakistan has framed polices and laws related to climate change however, the challenge is the implementation of these polices and initiatives which is directly related to climate change awareness and literacy. This study addresses the central question of what the status of climate change awareness and literacy and what role media and social actors play in this regard. To answer this question, a qualitative, descriptive, and analytical methodology has been employed. This study found that poor climate literacy and awareness among common masses is one of the key reasons that so far these initiatives are not successful. Since the real chain movers of any response and development are people not policy makers or power elites so nourishing eagerness for climate change literacy and awareness proves effective. This study recommends that as a nation, it is necessary to develop climate literacy and awareness to generate public response against the imminent threat of climate change.
\end{abstract}

Keywords: Climate Change, Media, Literacy, Civil Society, Local Government, Climate Change Awareness.

\section{Introduction}

The modern-day concept of climate change typically reflects environmental changes brought about by anthropogenic involvement in the ecosystem. Climate change has become one of the grave issues of environment humans have ever witnessed (Moser \& Dilling, 2004). Although the issue is centuries old but it has attracted public attention only in 1980s (Seacrest et al., 2000). Since then, the environment conscious people have been showing their concern over results of anthropogenic involvement in the climate to alarming level that are posing critical threats to geophysical, social, and economic structures. To alarm the world, the then UN Secretary General, Antonio Guterres remarked "climate change is indeed running faster than we are, and we have the risk to see irreversible damage that will not be possible to recover if we don't act very, very quickly" (Guterres, 2018). United Nation Framework on Climate Change Convention defines it as "Climate change means a change of climate which is attributed directly or indirectly to human activity that alters the composition of the global atmosphere and which is in addition to natural climate variability observed over comparable time periods" (UNFCCC, 1992). Climate change refers to continuous and long-term changes 
to weather and climate patterns that cast negative impacts on human life. The Climate Change is the most debated and threatening issue of the recent civilized world.

Climate change has unparalleled implications on people settlements, cultivation of food, water resources and energy. Although the share of developing countries in the emissions of Greenhouse Gases is much smaller than developed countries but reliance on climate sensitive sectors like water, and agriculture are the main reasons behind their vulnerability. Pakistan shares common features with developing countries and is sixth among the vulnerable countries to climatic changes (Javed, 2016). Pakistan adopted its national policy on climate change in 2012 and by now it has full-fledged ministry on climate change. However, one of the key challenges for the implementation of these initiatives and policy response is poor climate literacy and awareness. Climate literacy and awareness empowers and mobilizes the masses to react and respond to the issue by deploying common efforts.

Globally, there are two main approaches to face the issue, the mitigation and adaptation. The mitigation approach refers to focus on activities and initiatives to reduce Greenhouse Gas (GHG) emissions. Mitigation actions serve the aim to stabilize and decrease the quantity of GHGs in the atmosphere for stopping many harmful effects of the climate change. Yet, despite all the mitigation measures, anthropogenic GHG is already rooted in the atmosphere. Therefore, adaptation approach is adopted which refers to reducing the exposure of natural and human systems to the impacts of climate change by adjusting our existing social, ecological, and economic systems according to changes happened in climate (Anderson, 2010). These two approaches demand the climate literacy and awareness of the public, literary circles and key actors of climate change response. In case of Pakistan, there is lack of common awareness and literacy in public, educated circles and key actors. This is one of the main reasons that we are not on the right track in our response to climate change.

Climate change, one of the threatening issues of the $21^{\text {st }}$ century bears serious effects on foodstuff and availability of water. The issue not only causes fluctuations in the monsoon rains and snow melting which result in torrents but also helps rise the sea level which causes hurricanes (Scheffran, 2011). The frequent disasters with great magnitude could pose severe problems for population of the entire world, especially, the developing countries that are reckoned as vulnerable to climate change. Douglas and Wildavsky (1982) in 'Cultural Theory of Risk' believes that culture usually reflects an array of received views, beliefs, and ideas. It also represents ways of conduct that are learnt, shared, and changed by individuals as members of a particular society. This culture, according to Douglas is omnipresent, provides directions and attaches meanings to perceived views about the climate threats, guide decisions regarding tackling the issue and prompts subsequent actions. The theory further suggests that "institutional cultures" carry positive implications for looking at the issue of climate change and proposing ways and means for mitigation and adaptation, and prompting effective actions.

\section{Research Methodology}

This research is purely qualitative and involves content analysis of the existing research on the issue. The study adopts descriptive analytical approach to critically review the available material. The study mostly reviewed the contents with respect to nature of the issue of clime change, causes of climate change and global warming. This research also incorporated review of literature about climate change awareness and literacy, and role of media and other (social) actors such as civil society, local government, lady health workers and educational institutions. 
The paper attempts to analyse the climate literacy and awareness with the causes behind poor performance regarding adaptation and mitigation practices. Secondly, it presents a selfsustained solution for the promotion of climate awareness and literacy through existing institutions and resources. To have better insight into the issue, some useful available material like, research papers, books, articles, working papers, reports of international organizations, and official documents and reports of government of Pakistan are reviewed. This paper is divided into four sections and each section is further divided into subsections. Section one deals with introduction, section two gives overview of the relevant theory. Section three narrates methodology of the study. Section four enlightens climate change and Pakistan vulnerability. Section five discusses concept of climate awareness and literacy, and section six present the idea of promoting climate awareness through existing institutions and resources.

\section{Climate Change and Pakistan's Vulnerability}

It is now an established fact that Climate Change is directly correlated to Greenhouse Gas (GHG) Emissions. GHG emission is mostly caused by imbalances in human activities. The Inter-governmental Panel on Climate Change predicts increase in global temperature from 3.5C to 4C till 2100 (IPCC, 2014). The climate change issue is contributing to so many socioeconomic problems across the globe. However, the vulnerability in Afro-Asian regions is much higher as compared to other regions (Kiran \& Qurat-ul-Ain, 2017). Developing countries are more vulnerable to climate change than the developed world. Although, the share of developing countries in GHG emissions is much smaller than developed countries, the climate change is likely to have considerable implications on the economies of developing countries because of their dependency on climate sensitive sectors (Ludwig et al., 2007). Pakistan as a developing country shares the same fate with other Afro-Asian countries in terms of socio-economic effects of the climate change. Pakistan is having changes in monsoon rain patterns. The cost it has to pay is water and food scarcity, health and hygiene concerns and mass relocation, (Pakistan 2025, 2015). Pakistan's natural resources and economy are predominantly dependent on agriculture. It constitutes almost 21 percent of GDP and accounts for half of the employed labour and for the largest share of foreign earnings (Javed, 2016).

Pakistan contributes only one percent to total emission of Greenhouse Gases. However, its 200 million people are in constant danger of climate change. According to Global Climate Risk Index, 2018, Pakistan is among ten states mostly affected by climate change (The Express Tribune, 2020). In the year 2018, more than 100 people have lost their lives due to heart related illnesses across the country (Salam, 2018). In Pakistan, there are three most important implications of climate change; water security, food security and energy security. The country is already facing scarcity of water and energy that are threatening socio economic fabric of the Nation. Another alarming risk of climate change is the occurrence of natural disasters like, floods, droughts, extreme temperature, land sliding etc. The devastating floods have been occurring since 2007 . The flood in 2010 brought heavy miseries in shape of men and material loses. The current drought in Tharparkar district of Sind has been prevailing since 2008, taking precious lives of children's every day. The extreme weather events like heat stroke occurred in every summer season in most part of the country.

\subsection{Climate Change Awareness and Literacy}

Climate change awareness refers to familiarity with key concepts of climate change. Climate literacy is scientific term refers to include climate learning through introducing climate 
curriculum in education system. However, sometimes these terms are used interchangeably. The climate literacy refers to systematically including climate related learning in education system. "Climate literacy is an understanding of the climate's influence on you and society and your influence on climate" (NOAA, 2008). Climate literacy includes, understanding the core canons of all aspects of the earth system. It also includes the knowhow to assemble reliable information about climate and weather and communication of the same in objective oriented and meaningful way (Miler \& Sladek, 2011). "Literacy and awareness are an essential element of the global response to climate change. It helps people to understand and address the impact of global warming, increases 'climate literacy' among young people, encourages changes in their attitudes and behaviour" (UNESCO, 2014). Proper literacy, awareness, skills, and behaviour is prerequisite of successful climate change response. Education enables individuals and communities to respond in better way and play role in combating the issue (Anderson, 2010). Unfortunately, people in Pakistan do not conceive climate change as a real threat because of lack of required awareness and literacy. According to Article- 6 of UN Convention on Climate Change, the parties to convention are required to encourage education, training and public awareness programs within own capacities and assets (UNFCCC, 1992).

The climate change awareness sensitizes and mobilizes masses to pay attention to the problem and take collective steps to face the danger. Climate change awareness without any doubt has an important role in creating green thinking in people's minds. However, creation of climate awareness is not an easy task. Given this, it should be given important place in any policy and initiative. The awareness and literacy on climate would help to cope with changes occurred in climate and environment (Rauf, 2017). The main issue in Pakistan is the lack of public awareness on climate change (National Climate Change Policy, 2012). But it is not confined to public only. The same is also lacking in educated class and even key climate actors. Literacy regarding climate change issues is not the field of experts and policymakers alone, common citizens also need to be knowledgeable concerning the impacts of climate change and likely adaptation and mitigation measures (Planning Commission of Pakistan, 2010). It is high time to address the issue at both the macro and micro levels, through trainings, awareness campaigns, and education curriculum re-adjustment. The gap in research and implementation also needs to be covered, with focus on research conversion into policy implementation (Javed, 2016). Raising climate change awareness at the local level is critical as climate change impacts have the potential to create devastating effects on the socio-economic structure of Pakistan (Shahid \& Piracha, 2016).

\subsection{Causes of Low Climate Awareness and Literacy in Pakistan}

Firstly, lack of political will and commitment contribute to the low climate awareness and literacy in the country. There is an outcry of climate change around the world but we have not yet formed a national level program for climate awareness literacy. Secondly, education systems prove to be the base for public awareness and literacy, yet we have failed to adjust our system according to emerging needs. Climate change has not been included as core issue in national educational curriculum of the land (Khan, 2016). Thirdly, in Pakistan, the focus is on only job-oriented aspect of education. People mainly focus on the fields and subjects that facilitate employment. Fourthly, there is complete absence of community awareness programs on climate change. In other developing countries like India and Bangladesh, climate change awareness is linked with other programs. Fifth, civil society and non-governmental organizations play important role in creating public awareness but in societies like ours, they are stigmatized as liberals and seculars who promote western culture. Likewise, print, and 
electronic media across the globe operate to create public awareness regarding national issues. But unfortunately, here in Pakistan, media houses are run only for commercial gains. Rush to break news and panic and sensationalism have become norms of Pakistani media. This non profitable issue of climate change has no or little place in the contents of Pakistani media.

\section{Utilization of Existing Institutions for Climate Awareness and Literacy}

In this section, we are going to discuss three prospective strategies for the promotion of climate literacy and awareness. The most important feature of these strategies is that they are based on existing institutions and resources. We can utilize the existing institutional setup to improve climate awareness and literacy.

\subsection{Educational Institutions for Climate Awareness and Literacy}

According to 1973 Constitution, the power distribution formula of Pakistan, the legislation, execution and oversight powers of education and literacy come in the provincial domain. Furthermore, the legislation and implementation of climate change initiatives also rest with provinces. Central government only has the power to direct provinces to fulfil international commitments on climate change. Given this, formal education model for the promotion of climate awareness can be useful for our provincial governments. The education system in Pakistan is divided into 5 levels: Primary (Pre-primary to grade-5), Middle (grade 5-8), Secondary (grade 9-10), Higher Secondary (grade 11-12), and University Education (grade 12 - PhD) (Janjua, 2013). To promote climate change awareness and literacy, it is prompt to include climate change related contents in existing syllabus and co-curricular activities from pre-primary to university education. These contents can be included in three ways in the existing scheme of studies (see below table).

\begin{tabular}{|c|c|c|}
\hline Level & Grade & Contents \\
\hline $\begin{array}{l}\text { Pre- } \\
\text { Primary }\end{array}$ & Nursery \& Prep & $\begin{array}{l}\text { Alphabets, Words meaning, playing activities } \\
\text { related to climate change (CC) }\end{array}$ \\
\hline Primary & $01-05$ & $\begin{array}{l}\text { Simple learning of what is around us - Introduction } \\
\text { to sky, earth, atmosphere, solar system, sun, } \\
\text { energy, use of energy etc. }\end{array}$ \\
\hline $\begin{array}{l}\text { Middle } \\
\text { Schooling }\end{array}$ & $\begin{array}{l}\text { 06-08: These contents can be } \\
\text { systematically included in } \\
\text { General Science and Social } \\
\text { Study curriculum. Essays, } \\
\text { stories, dramas, speeches on this } \\
\text { topic in the subjects like English } \\
\text { and Urdu may be introduced. }\end{array}$ & $\begin{array}{l}\text { Earth's Energy Balance } \\
\text { Greenhouse Gases and Energy Balance } \\
\text { Introduction to Climate Change } \\
\text { Climate Change Debate } \\
\text { Mitigation Strategies } \\
\text { Impact, Adaptation, and Mitigation of Climate } \\
\text { Change }\end{array}$ \\
\hline $\begin{array}{l}\text { Secondary } \\
\text { Schooling }\end{array}$ & $\begin{array}{l}\text { These are general contents for } \\
\text { both arts and science students. } \\
\text { Other scientific contents can be } \\
\text { included in Science subjects like } \\
\text { physics, chemistry etc. }\end{array}$ & $\begin{array}{l}\text { Global implications of CC } \\
\text { Water, energy, and food implications } \\
\text { Health, Education, and other social implications, } \\
\text { Mitigation approach } \\
\text { Adaptation approach } \\
\text { Specific implications on Pakistan } \\
\text { Pakistan mitigation and adaptation strategy } \\
\text { Role of teachers, students, and community in } \\
\text { addressing CC. }\end{array}$ \\
\hline
\end{tabular}

Source: San Francisco Climate Education Project (2018) 


\subsection{Role of Media in Creating Climate Change Awareness and Literacy}

The tools and devices that are used to communicate are termed as media. Media through its contents, serve informational, entertainment, educational and promotional purposes. The classic media includes: television, radio, magazines, and newspapers. Modern media includes social media that is widely used throughout the world via internet (Ashraf \& Islam, 2014). It plays the role of a bridge between people and government. Media form and gauge public opinion in favour or against any cause, movement, or activity. It creates awareness of the dayto-day happenings and issues of national and international concerns. Media in Pakistan sets agenda for public opinion, it sets environment for human development, it links government and people, and it raises public issues for solution (Hanan et al., 2016). Keeping in view its power, media can also play active role in creating public awareness on climate change and urge the policy makers to take their part. This system of communication can also be used to disseminate relevant information and stuff from scientific and policy circles to public (Kakade et al., 2013). Media liability is not only confined to pouring information. But it needs to draw public attention through its reliable and credible stuff towards climate concerns such as food, water, energy, and health. The public in turn can put pressure on government for active response (Riaz, 2018).

There are more than 2000 Newspapers and over 100 TV channels in Pakistan. Beside social media, these communication tools are the major sources of information and entertainment. What the government needs to do is to regulate these tools by making some relevant laws. All media organizations can be directed and forced through implementation of these laws to include substantial amount of stuff regarding climate change. For this purpose, some positive steps of the government to use Pakistan Electronic Media Regulatory Authority (PEMRA) have already been taken. The Pakistan Electronic Media Regulatory Authority has issued a notification to direct TV channels for playing public service message on the importance of water conservation and fund collection for Muhmand Dam. According to this notification, media organization are directed to assign one minute in every hour during the morning shows and repeat this during the prime time from $7 \mathrm{pm}$ to $12 \mathrm{pm}$ for public service messages with respect to fund raising (Khan, 2018). The same types of direction should be given to all TV channels, print media houses and social media sites to allocate prime time segments for climate change awareness. All TV channels should be directed to incorporate panel discussion programs on climate change in their prime-time transmission. Climate experts, educationists, media professionals and social scientists should make part of these panels. Discussions in these programs are likely to improve awareness level of the masses regarding climate change and would help encourage the policy makers to step farther in addressing the issue.

\subsection{Climate Awareness through Civil Society}

Civil society members and organizations around the world play important role in creating awareness and promoting the cause for any movement or activity. Given the complexity of modern states, it becomes difficult for governments to address multifaceted issues and cater to the needs of their respective societies. This gap is usually filled by civil society organizations as social actors. The term civil society refers to associations and structures in which people are organized to achieve common objectives based on common ideas. Non-governmental organizations are also considered as important part of civil society. Peasants and professional associations, community-based organizations, environmental groups, independent research institutes, universities, faith-based organizations etc., are also made part of the civil society. 
Some scholars have included trade and professional unions, cultural and support associations, and religious groups in the domain of civil society (Clayton et al., 2000).

The civil society organizations perform several functions in a society. They create awareness with respect to public issues, service delivery, protect citizens from unlawful interference of government, and people empowerment etc. Like other countries of the world, civil society organizations play important role in Pakistan. The Civil society organizations in Pakistan contribute a lot to the promotion of human rights, education, health, democracy, women empowerment, poverty reduction and other socio economic and political fields (Bhattacharya, 2016). Though, some civil society organizations around the world have been working on climate issues, especially, in awareness creation and advocacy since long. But only recently, several such organizations in Pakistan have decided to form civil society coalition for climate change. In this coalition, some international organizations, and institutions of repute such as World Bank, UNDP and other national civil society organizations are given due place. The coalition is officially licensed and is budgeted by the European Union. It provides an extended platform to civil society organizations, climate experts, researchers, media, and other actors for their collaborative efforts (Shahid \& Piracha, 2016; Shahid, 2017). Unfortunately, coalition's efforts serve no good to common people rather most of its activities are designed to facilitate key government officials, civil society organizations and other power elites in Pakistan.

It is high time to overhaul the system and encourage the civil society organizations to dedicate themselves to creating public awareness regarding issues of national and international concerns. The issue of climate change, one of the mot burning and debated issues needs to be talked by the civil society organizations. There is a strong need to take steps to start programs to promote public awareness in relation to the stated issue. The civil society organizations can contribute to climate awareness by adopting initiatives that are aimed at mass awareness. These organizations should provide financial and technical support to NGOs and Community organizations for starting initiatives for public awareness and response to climate change. Collaborating with media and educational institutions, these organizations should initiate mass awareness campaigns on climate change in every nook and corner of Pakistan.

\subsection{Local Government and Climate Awareness}

Local Government institutions around the world play important role in the climate change response. As in other countries so in Pakistan, the local government institutions provide a useful platform for creating awareness of local community on important issues like climate change. Local government system is considered as foundation and real essence of democracy. Every democratic country of the world maintains well-established local government system. The basic objective of the local government system is to facilitate and serve people at their doorsteps. In Pakistan, the history of local government system is filled with trial versions. The country has already tried three local government systems all during martial law governments. The first local government system was introduced in 1958 under General Ayub Khan martial law government. It was established under Basic Democracies Ordinance 1959. It was four tiers system adjusted hierarchically (Cheema et al., 2006). In 1979, the LG system was revived and re-implemented under General Ziaul Haq martial law regime. It was practically a three-tier system designed to prolong martial law. The third experiment was started by General Musharraf regime in 2001. The system still exists and is considered the most effective and extensive local government system. For the first time in Pakistan's history, the district bureaucracy was given under the control of elected District Nazim (Cheema et al., 2006). 
Most of the countries empower local government to play their due role in awareness creation, mitigation, and adaptation to address the issue of climate change. Local government institutions in the UK implement different initiatives to promote awareness about climate change, especially, use of energy and its implications (Bulkeley \& Kern, 2006). Currently, local governments in many states are working on many initiatives related to climate change. These initiatives include; awareness on climate change through local body members and panchyats, promotion of recycle and reuse of wastewater, use of energy saving led lamps and ban on plastic bags, schools' campaigns for awareness and use of bicycle (Modi, 2010). Even though Pakistan is facing terrible impacts of climate change in the form of destructive floods, water and energy scarcity and droughts, there is no significant contribution of local governments related to climate change.

\subsection{Climate Change Awareness through Lady Health Workers Program}

Lady Health Workers (LHW) program is another institutional set up in Pakistan that have direct link with local community, especially, with women and children. The LHWs have direct access to people even inside houses. They play key role in creating awareness on mother and child health issues. This program can be very useful in awareness creation on climate change. Pakistan initiated the same program in 1993 with the aims to provide health education and awareness and promote family planning etc. The women from local community having middle school certificates and received six months training are hired to deliver the services. Each LHW deliver services to nearly 200 families (Jalal, 2011). The rationale for using health worker program for climate change awareness is quite strong. Climate change has direct implications on human health and has caused so many diseases. Vector borne and waterborne infectious diseases are emerging and spreading mainly due to climate change. For example, the prevalent Malaria in the highlands of East Africa was previously not existing there (Shuman, 2010). According to WHO, climate change will increase the burden of global diseases. By 2030, there will be ten percent more increase in diarrheal diseases. Children are more vulnerable to other diseases like pneumonia, cholera etc. (World Health Organisation, 2009).

Many countries are integrating climate change adaptation with health sectors, especially, with primary health care services. The climate change has direct impacts on all living beings. The health implications of climate change should be considered at all levels of policy and decision making. So much vulnerable to climate change, Pakistan needs to have awareness and capacity building of health care providers on climate change (LEAD Pakistan, 2013). LHWs are playing critical role in public health delivery system throughout the country. Most of them are performing their duties in remote areas of the country (HRCP, 2018). Given their reach to far flung areas of the country, LHW services can contribute a lot to creating awareness and literacy about climatic changes in the ecosystem.

\section{Conclusion}

Climate Change awareness and literacy is one of the key preconditions to respond to the issue efficiently. General mass participation in the mitigation and adaptation activities largely depends on the level of their awareness and literacy on climate change. Pakistan is one of the most vulnerable countries to climate change and needs strong response from all segments of the society. But as a nation, our poor awareness level and literacy on climate change hinders efficient collective response. This study analysed Pakistan's vulnerability and state of climate 
awareness and literacy. After analysing the situation through relevant literature, it was revealed that lack of climate awareness and literacy prevails in Pakistan.

The causes that led to lack and poor climate awareness and literacy are investigated as lack of political will and commitment, traditional education system, no climate curriculum, no national program for climate awareness, and lack of media initiatives. Likewise, poor economy of the country contributed a lot to non-allocation of substantial budget for taking new initiatives with respect to creating awareness and literacy on climate change. Given this, the study suggested and recommended to utilize existing institutions and resources by integrating climate change in their activities. The prospective institutions that can play their due role in awareness on climate change are formal education system, media, civil society organizations, local government and LHW program. These institutions can be utilized for climate awareness and literacy with slight modifications in their existing structure, powers, and responsibilities. Through this, we can increase the climate awareness and literacy that can play an important part in our national response to the issue of climate change. We need commitment at individual to government level to address the issue. Collective action and concerted efforts of the entire nation can help reduce the havocs of the much-debated issue of climate change.

\section{References}

Anderson, A. (2010). Combating climate change through quality education. Brookings Global Economy and Development. https://www.preventionweb.net/files/15415_15415brookingspolicybriefclimatecha.p $\underline{\mathrm{df}}$

Ashraf, M. \& Islam, U. M. (2014). Media activism and its impacts on the psychology of $\begin{array}{llll}\text { Pakistani } \quad \text { society. } & \text { ISSRA }\end{array}$ https://ndu.edu.pk/issra/issra_pub/articles/issrapaper/ISSRA_Papers_Vol6_IssueI_2014/03-Media-Activism-MuhammadAshraf.pdf

Bhattacharya S. (2016). Civil society in Pakistan: functioning and challenges. South Asian Journal of Multidisciplinary Studies (SAJMS), 3(3), 24-45. http://sajms.com/wpcontent/uploads/2016/04/Article-Civil-Society-in-Pakistan.pdf

Bulkeley, H., \& Kern, K. (2006). Local government and the governing of climate change in Germany and the UK. Urban Studies, 43(12), 2237-2259. https://doi.org/10.1080\%2F00420980600936491

Cheema, A., Khwaja, A. I., \& Qadir, A. (2006). Local government reforms in Pakistan: context, content and causes. 381-433. https://epod.cid.harvard.edu/sites/default/files/201802/local_government_reforms_in_pakistan-_context_content_and_causes.pdf

Clayton, A., Oakley, P., \& Taylor, J. (2000). Civil society organizations and service provision (pp. 1-23). United Nations Research Institute for Social Development. https://citeseerx.ist.psu.edu/viewdoc/download?doi=10.1.1.489.1987\&rep=rep1\&ty pe $=$ pdf

Douglas, M., \& Wildavsky, A. (1982). Risk and culture: an essay on the selection of technical and environmental dangers. University of California.

Guterres, A. (2018, September). Climate change is indeed running faster than we are, and we have the risk to ....... Remarks at High-Level Event on Climate Change; UN Headquarters. https://www.un.org/sg/en/content/sg/speeches/2018-09-26/remarkshigh-level-event-climate-change. 
Hanan, M. A., Saleem, N., Ali, A., \& Mukhtar, S. (2016). Role of media in strengthening democracy in Pakistan: journalists' perception. South Asian Studies, 31(1), 331-345. http://111.68.103.26/journals/index.php/IJSAS/article/viewFile/3050/1261

HRCP (2018). Human Rights Commission Report (2018). https://www.ecoi.net/en/document/2007056.html.

IPCC. (2014). Climate change 2014: synthesis report. Contribution of Working Groups I, II and III to the Fifth Assessment Report of the Intergovernmental Panel on Climate Change

(IPCC). https://www.ipcc.ch/site/assets/uploads/2018/05/SYR_AR5_FINAL_full_wcover.p $\underline{\mathrm{df}}$

Jalal, S. (2011). The lady health worker program in Pakistan-a commentary. European Journal of Public Health, 21(2), 143-144. https://doi.org/10.1093/eurpub/ckq199

Janjua, Q. A. (2013, June 8). Education system in Pakistan. Hamari Web. https://hamariweb.com/articles/34123

Javed, S. A. (2016) Climate change reflections on issues and way forward. Development Advocate Pakistan, 2(4), https://www.researchgate.net/publication/299393218.

Kakade, O., Hiremath, S., \& Raut, N. (2013). Role of media in creating awareness about climate change: a case study of Bijapur City. IOSR Journal of Humanities and Social Science, 10(1), 37-43. http://www.iosrjournals.org/iosr-jhss/papers/Vol10issue1/F01013743.pdf?id=6197

Khan, S. (2018, August 09). PEMRA advises channels to allocate ad spots, hold fundraising telethons for dams. The Dawn News. https://www.dawn.com/news/1425959

Khan, S. (2016). Climate Change: Perspective of a Civil Society Organization Development advocate Pakistan, 2(4). https://www.researchgate.net/publication/299393218.

Kiran, A. \& Qurat-ul-Ain (2017). Climate change implications for Pakistan and way forward. ISSRA Papers, 9(2), 49-62. https://www.ndu.edu.pk/issra/issra_pub/articles/issrapaper/ISSRA_Papers_2nd-Half-2017/08.Climate-change-and-implications-for-

National-Security-11-Dec-2017.pdf

Lead Pakistan. (2013). Incorporating climate change considerations in health policy of Punjab. Leadership for Environment and Development. https://lead.org.pk/

Ludwig, F., Van Scheltinga, C. T., Verhagen, J., Kruijt, B., van Ierland, E. C., Dellink, R. B., \& Kabat, P. (2007). Climate change impacts on developing countries-EU accountability (No. PE 393.511). European Parliament. https://www.europarl.europa.eu/thinktank/en/document.html?reference=IPOLENVI_ET(2007)393511

Miler, T., \& Sladek, P. (2011). The climate literacy challenge. Procedia-Social and Behavioural Sciences, 12, 150-156. https://doi.org/10.1016/j.sbspro.2011.02.021

Modi, J. V. (2010). Current initiatives of local governments in India, climate change related issues. https://www.city.hamamatsu.shizuoka.jp/foreign/english/intercity.

Moser, S. C., \& Dilling, L (2004). Making climate hot: communicating the urgency and challenge of climate change. Environment: Science and Policy for Sustainable Development, 46(10), 32-46. https://doi.org/10.1080/00139150409605820

National Climate Change Policy (2012, September). Ministry of Environment, Government of Pakistan. http://www.nrsp.org.pk/gcf/docs/National-Climate-Change-Policy-ofPakistan.pdf

NOAA, (2008). Climate literacy: essential principles and fundamental concepts. https://www.climatechangeeducation.org/pdf/climate_literacy_k-12.pdf. 
Pakistan 2025. (2015). Ministry of Planning, Development \& Reform. https://www.pc.gov.pk/uploads/vision2025/Pakistan-Vision-2025.pdf

Planning Commission of Pakistan. (2010). Task force on climate change final report. https://www.gcisc.org.pk/tfcc final report.

Rauf, A. M. (2017, April 22). Climate and environmental literacy is the key to sustainable future. Gulf News. https://gulfnews.com/opinion.

Riaz, S. (2018). Role of media in climate sensitization. Pakistan Journal of Social Sciences (PJSS), 38(1), 152-165. https://media.teckiz.com/pakistan-journal-of-socialsciences/pjss-bzu/2020/05/21/5ec663551fde1.pdf

Salam, A. (2018 July 24). Pakistan is ground zero for global warming consequences. USA Today. $\quad$ https://www.usatoday.com/story/news/world/2018/07/24/pakistan-oneworlds-leading-victims-global-warming/809509002/

Scheffran, Jurgen, (2011). The security risks of climate change: vulnerabilities, threats, conflicts and strategies. In: Brauch et al. (Eds.): Coping with global environmental change, disasters and security. Hexagon Series on Human and Environmental Security and Peace. Springer.

Seacrest, S., Kuzelka, R., \& Leonard, R. (2000). Global climate change and public perception: the challenge of translation. Journal of the American Water Resources Association, 36 (2), 253-263. https://doi.org/10.1111/j.1752-1688.2000.tb04265.x

Shaid, J. (2017, May 04). Civil society organizations come together against climate change. The Dawn News. https://www.dawn.com/news/1330941

Shahid, Z., \& Piracha, A. (2016). Awareness of climate change impacts and adaptation at local level in Punjab, Pakistan. In Balanced Urban Development: Options and Strategies for Liveable Cities (pp. 409-428). Springer. https://link.springer.com/chapter/10.1007/978-3-319-28112-4_25

Shuman, E. K. (2010). Global climate change and infectious diseases. New England Journal of Medicine, 362(12), 1061-1063. https://www.nejm.org/doi/full/10.1056/NEJMp0912931

The Express Tribune (2020, December 28). https://tribune.com.pk/story/2111626/1-climatechange-pakistan-5th-affected-country-1999-2018-report

UNESCO. 2014. Climate Change Education and Awareness. https://en.unesco.org/themes/addressing-climate-change/climate-change-educationand-awareness

UNFCCC. (1992). United Nations Framework Convention on Climate Change. https://unfccc.int/resource/docs/convkp/conveng.pdf.

World Health Organization (2009). Climate change and human health. https://www.who.int /. 